\title{
Conceptual model of the national pedagogical university education
}

\author{
Aleksandr Gluzman ${ }^{1}$, Nataliia Gorbunova ${ }^{2}$, and Alina Gluzman ${ }^{3 *}$ \\ ${ }^{1}$ V.I. Vernadsky Crimean Federal University, Republic of Crimea, Simferopol, Prospekt Vernadskogo \\ 4, Russia. \\ ${ }^{2}$ V.I. Vernadsky Crimean Federal University, Republic of Crimea, Simferopol, Prospekt Vernadskogo \\ 4, Russia. \\ ${ }^{3}$ V.I. Vernadsky Crimean Federal University, Republic of Crimea, Simferopol, Prospekt Vernadskogo \\ 4, Russia.
}

\begin{abstract}
The article substantiates a conceptual model of pedagogical university education, which is relevant due to socio-economic phenomena occurring in society. The creation of a systemic concept of pedagogical university education provides an opportunity for the development and implementation of technologies for specialists' professional and pedagogical training at the university.
\end{abstract}

\section{Introduction}

The analysis of the experience accumulated in national and foreign universities provides an opportunity to substantiate the conceptual model of pedagogical university education. The need for such concept is due to socio-economic phenomena occurring in society: the strengthening of democratic tendencies and the increasing role of universal values, the development of integration processes in science, education, the formation of market relations, the development of national culture $[1,2]$.

The increasing role of universities in the scientific, educational and sociocultural significance, the need to transform federal universities into regional scientific, educational and production complexes require the creation of a new, systematic concept of pedagogical university education. At its center should be a free, socially active, creative and spiritual personality of a university student, whose training should be adequate to the content and realization methods of the forthcoming professional activity, correspond to the psychological nature of pedagogical work.

The need for a new concept of pedagogical university education is associated with the existence of significant weaknesses in the system of higher and, in particular, university education, which is still under the influence of subjectivity and command-administrative management style. University education is still characterized by the conservatism of the content, forms, methods of teaching and upbringing, the predominantly informational nature of education to the detriment of preparation for practical activities, personal

\footnotetext{
* Corresponding author: alina-gluzman@mail.ru
} 
development and familiarization with a wider world culture, a low level of teachers' psychological and pedagogical training and isolation from world achievements in this area.

\section{Methods}

When writing an article, methods of analysis of scientific literature, periodic articles, and publications on the topic were used.

\section{Results}

The proposed concept of university pedagogical education was developed taking into account the historical lessons of the national university system development and foreign experience of specialists' professional and pedagogical training, based on the results of creative searches of pedagogical teams and individual scientists of Russian universities. In developing the concept a systematic approach was used as a methodological basis. According to its systemic-structural, systemic-functional and systemic-genetic manifestations, pedagogical university education is considered in three interrelated aspects: content, functioning and development. According to this, university pedagogical education is not a static system, but a developing and self-developing one in the concept $[1,2]$.

The essence and goals of pedagogical university education. The essence of university education consists of an interconnected set of training, education and upbringing, aimed at achieving a single goal of forming a harmoniously developed personality. All components of the pedagogical process are closely interconnected, without losing their autonomy, features inherent only in this internal process. Thus, the dominant function of university pedagogy is upbringing, the function of education is training, and the function of learning, respectively, is learning. However, it is impossible to become an educated person without receiving a proper upbringing, the learning process in general is closely connected with upbringing and education, carrying out a person's developmental activities and cognitive activity. Carrying out the pedagogical process, it is necessary to highlight clearly the part of the pedagogical influence that dominates at the current moment. The main goal of training is to transfer certain knowledge to students, thus, the teacher needs to be clearly aware of a direct impact of the learning process onto education, and especially human self-education. A person's upbringing largely determines his attitude to education, arise motivation, forms goals, that may include the desire to get education. The purpose of university education for students is learning. In the modern world, everyone should understand that education is the foundation for future work, and it depends only on yourself and your competency. Visiting classes, working with literature, searching for options for the knowledge practical application, participating in scientific conferences are mandatory events for every student.

The purpose of the university is to organize innovative educational and professional programs getting the opportunity for starting own business or to find a job; teaching staff, who are not only knowledge monopolists, but also facilitators of their acquisition, educational and career coaches, professionals in the field of education and science, successful representatives of various industries; a variety of teaching methods: business games, hackathons, workshops, educational trips, etc. The integrative result of pedagogical university education is a socially active, free, creative and spiritual personality with a marked pedagogical and research orientation, capable of adapting to various types of pedagogical activity in changing socio-economic conditions.

Types and forms of pedagogical university education. The system of university pedagogical education includes classical and specialized universities, pedagogical institutes, faculties, departments and specializations, historically formed in universities of 
the Russian Federation, as well as a subsystem for training specialists with degrees in the field of vocational education, forms of mastering pedagogical qualifications in the postgraduate period. The pedagogical education system also includes teacher training colleges operating at universities and interacting with them. Forms of pedagogical education can be developed on a state, municipal, commercial basis, being subdivided into full-time, part-time and evening ones.

The system of pedagogical university education focuses on the individual and creative training of teachers of various specialties, specializations and profiles. This is manifested, first of all, in overcoming the narrow-departmental disciplinary approach to building the nomenclature of specialties, introducing differentiated teachers' training in relation to the main types of their future professional activities, strengthening functional specialization. The comparison of national and foreign pedagogical university education provides an opportunity to determine the specifics of training graduates in their specialty, specialization and profile $[3,4]$.

The content and structure of pedagogical university education. Education as the level of knowledge, gained in the learning process, is one of the main factors of a person's socialization, his ability to philosophical comprehension of the integrity of human existence and culture. Education, being reformed in Russia today, has a special influence on the individual socialization. This process is taking place in the conditions of an acute economic crisis, a rapid change in worldview, and the national culture revival. Therefore, higher education should reflect the person's spirituality, which is formed under the influence of moral and spiritual values. The content of higher education is to provide such level of professional socialization that is necessary for successful activity in a particular area by society selected and recognized system of people's objective experience elements $[5,6,7,8,9]$.

The specialists' training in the system of university pedagogical education is carried out in accordance with the real needs in the teacher's activities of a specific specialty and depending on the orientation of the students' personality, their professional interests, abilities and capabilities. The content of such targeted training should be practically justified by developing the specialist profile, whom the entire training content is subordinated - from the beginning (general theoretical disciplines) to completion (pedagogical training).

Fundamental training of specialists is aimed at increasing the students' training level, formation of a competent qualified specialist, competitive in the labor market, who is oriented in related fields of activity, capable of working in his specialty at the world standard levels. Thus, the issue of developing pedagogical conditions and approaches for organizing the fundamental training process, which will contribute to the formation of the students' professional basic competence in a higher educational institution, is relevant.

The variable part of professional training is based on special training, executed by taking into account the characteristics of the scientific profile, in our case - pedagogical. Special training is most effectively implemented in conjunction with basic and specialized subject training, during which there is a mastery of theoretical and practical knowledge inherent in each narrow profession, the formation of skills and abilities system, the development of abilities and the acquisition of professional experience.

Cultural training involves the formation of a young specialist's worldview foundations, the development of creative potential and the increase of future teachers' level of the general culture through familiarization with the capital's artistic and cultural monuments, museums, theaters and the activities of prominent figures in Russian culture, which will contribute to the formation of culture and education unity, the upbringing of patriotism and national dignity, filling the professional activities of teachers with the knowledge of national and world culture. 
Research training of students is aimed at introducing elements of creativity into practical training. In such classes, students are faced with problematic situations that require finding an optimal solution. Students independently develop options for such solutions and justify the choice of the best one. The formation of research skills will be facilitated by: dialogue form of classes (formation of collective creativity skills), problem lectures, round tables, business games, forums, scientific and practical conferences, individual homework with elements of scientific research.

Practical pedagogical training involves passing all types of pedagogical practice: introductory, educational and pedagogical practice (it is passive, students are observers of the educational process); pedagogical and industrial practice (takes place in an active form, during which trainees have their own lessons, educational hours and attend lessons of students-colleagues with a detailed analysis) [3,10,11,12,13].

The technology of pedagogical university education. The content of the technology of pedagogical university education includes scientifically grounded and rationally selected scientific information and organizational forms creating conditions for motivation, stimulation and activation of educational and cognitive students' activities. The technology of pedagogical education includes a system of pedagogical and educational methods, techniques and methods of goal-setting, planning, organization, implementation, control, correction and assessment of educational and cognitive activity, which allows students to form a culture of educational and cognitive work. The function of the technology of pedagogical education consists in its focus on obtaining an integrative learning result for students, which is characterized by high quality and the maximum amount of learned educational information, dynamics, intensity, variability of teaching, as well as the universalization of knowledge, skills and methods of activity. The technology of pedagogical education provides:

- widespread use of active learning forms and methods, contributing to the intensification of educational-cognitive and professional-pedagogical activities;

- modeling of professional and pedagogical activities in the educational process in specialists training by designing, modeling and solving pedagogical situations, as well as transforming the methods of students' educational work into "educational and pedagogical skills" (V.V. Kraevsky);

- inclusion of students in professionally-oriented creative activity, involving the transfer of the acquired professional and pedagogical knowledge, skills, methods of activity to a wide area of pedagogical reality;

- individualization of student education, providing for the diagnosis and consideration of students' interests, inclinations, abilities and capabilities;

- predominance of various forms of self-education, involving the widespread introduction of new systems of communication and information technologies elements $[14,15,1,17,18]$.

The technology of pedagogical university education must correspond to the modern level of professional and pedagogical relations development, the requirements of the humanistic pedagogy of cooperation.

\section{Conclusion}

Thus, universities with their historically developed characteristics, content, structure and functions of education, fundamental training, humanitarian and research orientation represent a type of higher educational and scientific institution, where at the same time there is an opportunity to teach specialists of narrow, complex and integrative profiles. The creation of a systemic concept of university pedagogical education provides the chance for the development and implementation of technologies for specialists' professional and 
pedagogical training at the university. The new quality of teaching staff training in close connection with a radical improvement in their use is one of the main problems of university pedagogical education.

\section{References}

1. I. Yakovlev, Integrative processes in higher education (LGU publishing house, 1980)

2. A. Gluzman, Professional and pedagogical training of university students: theory and research experience (Search and Publishing Agency, 1989)

3. A. Gluzman, Personally-oriented preparation of university students for professional pedagogical activity: theory and practice (NAPS of Ukraine, 2012).

4. T.I. Sidnenko, Pedagogical potential of the legacy of A.S. Lappo-Danilevsky in the context of modernization of the educational environmen, Bulletin of Leningrad State University named after A.S. Pushkin, 2, 108-122 (2019)

5. A.A. Kuznetsov, Cross-platform project as a new form of organizing an electronic educational environment (using the example of the RCT), International Postgraduate Bulletin. Russian language abroad, 1, 33-40 (2020)

6. V.V. Petrov, E.V. Pokasova, Production of scientific knowledge in the conditions of higher school reform: problems and prospects, Philosophy of education, 3 (54), 64-73 (2014)

7. N.A. Maximova, Analysis of the model for building a unified information exchange system within the framework of a network educational space, Teacher and time, 13, $160-166$ (2018)

8. T.I. Zvorykina, L.V Silcheva, O.V. Gogaeva On the development of new standards as the main criterion for improving the quality of education, Bulletin of the Association of Tourism and Service Universities, 10 (3), 50-58 (2016)

9. V.M. Monakhov, S.A. Tikhomirov Evolution of the methodological system of elearning, Yaroslavl Pedagogical Bulletin, 6, 76-88 (2018)

10. E. White, L. King, Conceptual framework for scholarly communication guidance by the academic library: The case of Kwame Nkrumah University of Science and Technology, Journal of Librarianship and Information Science, 52 (4), 1137-1151 (2020)

11. J.V.D. Wirjawan, D. Pratama, E. Pratidhina, A. Wijaya, B. Untung, Herwinarso, Development of smartphone app as media to learn impulse-momentum topics for high school students, International Journal of Instruction, 13 (3), 17-30 (2020)

12. B. Jackson, S. Hauk, J.J. Tsay, A. Ramirez, Professional development for mathematics teacher education faculty: Need and design, Mathematics Enthusiast, 17 (2-3), 537-582 (2020)

13. K. Wang, J. Yin, Effects of Work Engagement on Professional Identity of Young Teachers in China's Ocean Colleges - Perspective of Psychological Capital, Journal of Coastal Research, 103 (1), 236-239 (2020) 
14. P.S. Angelle, D.J. Lomascolo, Principal voice for successful policy implementation: Lessons learned from teacher tenure, Research in Educational Administration and Leadership, 5 (1), 234-273 (2020)

15. S. Xue, A conceptual model for integrating affordances of mobile technologies into task-based language teaching, Interactive Learning Environments (2020)

16. E.K. Samerkhanova, E.P. Krupoderova, K.R. Krupoderova, A.V. Ponachugin, Creation of a Virtual Model of Educational Programs Management in a University, Lecture Notes in Networks and Systems, 602-609 (2019)

17. J. Mansyur, S.N. Kaharu, J. Holdsworth, A simple approach to teach newton's third law, Jurnal Pendidikan IPA Indonesia, 9 (1), 79-90 (2020)

18. K.W. Middleton, A. Donnellon, Personalizing entrepreneurial learning: A pedagogy for facilitating the know why, Entrepreneurship Research Journal, 4 (2), 167-204 (2020) 